\title{
Framingham Heart Study Cardiovascular Disease 10-Year Risk Score Clinical Classification
}

National Cancer Institute

\section{Source}

National Cancer Institute. Framing ham Heart Study Cardiovascular Disease 10-Year Risk Score Clinical Classification. NCI Thesaurus. Code C124707.

A standardized rating scale developed by D'Agostino et al in 2008, which is a genderspecific classification system used to estimate the 10-year risk of cardiovascular disease (CVD). This estimation takes into consideration of an individual's gender, age, smoking history, treatment for blood pressure, as well as systolic blood pressure, total cholesterol and high-density lipoprotein (HDL) cholesterol levels. 